Original Article

\title{
Evaluation of Antimicrobial Effects of Gouda Cheese Wax
}

Mojtaba Mohammadzadeh Vazifeh (PhD)Department of Microbiology and Microbial Biotechnology, Faculty of Life Sciences and Biotechnology, Shahid Beheshti University, Tehran, Iran

Seyed Masoud Hosseini

(PhD)Department of Microbiology and Microbial Biotechnology, Faculty of Life Sciences and Biotechnology, Shahid Beheshti University, Tehran, Iran

Ali Mohammadi iD

Department of Microbiology, Faculty of Biological Sciences, Alzahra University, Tehran, Iran

Mahdi Jahanfar

(PhD)Department of Microbiology and Microbial Biotechnology, Faculty of Life Sciences and Biotechnology, Shahid Beheshti University, Tehran, Iran

Hadi Maleki iD

(PhD)Department of Microbiology and Microbial Biotechnology, Faculty of Life Sciences and Biotechnology, Shahid

Beheshti University, Tehran, Iran

Corresponding author: Seyed Masoud Hosseini

Tel: +982129905913

Email: Ma_Hosseini@SBU.AC.IR

Address: Department of Microbiology and Microbial Biotechnology, Faculty of Life

Received: 2019/12/07

Revised: 2020/10/10

Accepted: 2020/10/14

\section{(c) (7) (9)}

This work is licensed under a Creative

Commons Attribution 4.0 License.

DOI: $10.29252 / \mathrm{mlj} .15 .1 .18$

\section{ABSTRACT}

Background and objectives: Gouda Cheese is regarded as a high quality and one of the most popular cheeses in the world. The defining characteristics of Gouda cheese are its yellow color, great aroma and taste of caramel sweetness. The cheese should be well chilled before waxing, to get better seal. The seal is very important to prevent contamination with molds and putrefactive bacteria. Cheese wax is made from paraffin with additional microcrystalline to make pliable for better seal. The aim of this study was to investigate antibacterial effects of Gouda cheese wax.

Methods: Gouda cheese wax samples were collected from four different manufacturers in Iran. The total count of coliforms, Escherichia coli, Salmonella, coagulasepositive Staphylococcus and mold and yeast on the samples was determined. The antimicrobial activities of Gouda cheese wax against E. coli, S. aureus, Saccharomyces cerevisiae, Aspergillus brazilissis and Salmonella enterica were investigated by determining minimum bactericidal concentration and minimum inhibitory concentration.

Results: The results indicated that all Gouda cheese wax samples were prepared in accordance with the national standards. In addition, the examined wax samples had no antimicrobial properties against the tested microorganisms.

Conclusions: The wax used in production of Gouda cheese in Iran has no antimicrobial properties.

Keywords: Escherichia coli, Cheese , Salmonella . 


\section{INTRODUCTION}

Gouda cheese is one of the most popular cheeses worldwide $(1,2)$. This semi-hard to hard cheese was first introduced in the Netherlands and was prepared from pasteurized cow's milk. Aged Gouda cheese have a strong flavor with a sharp yet sweet taste at the same time. Various microbial and chemical changes occur in the preparation of Gouda cheese. At the final stage of production, it is waxed with paraffin-based ingredients and then dried $(1,2)$. Production of this cheese include milk pasteurization, coagulation, cutting the curds, releasing the whey, moulding of cheese, brining, coating and maturing and storing (3-5).

There are International and National Standards on Gouda cheese that define the sensory, microbial, chemical, physical and packaging properties of this product. These standards also determine the microbial limitations for coliforms, Escherichia coli, Salmonella, coagulase-positive Staphylococcus, mold and yeast $(4,5)$.

According to Centers for Disease Control and Prevention in the US, a total of 113 outbreaks caused by cheese consumption were reported during 1998-2015, resulting in 2418 illnesses, 291 hospitalizations and 18 deaths (6).

Gouda cheese wax is obtained from petroleum derivatives. This type of wax can be recovered and used in a wide range of desirable applications. Paraffin and microcrystalline are widely used in the food industry because of their neutral properties. Paraffin with microcrystalline are used in packaging of various hard and semi-hard cheeses, such as Edam cheese and Gouda cheese. Edible paraffin and microcrystalline waxes are used to provide strength and waterproof properties (7-9). The function of the coating is to protect the cheese from microbial contamination while allowing moisture to evaporate. This coating is semi-permeable, which allows cheese to breathe and continue the maturation process (10).

Research plays an important role in increasing the longevity and improving the quality and safety of cheese products (11). The aim of this study was to evaluate antimicrobial effect of Gouda cheese wax and to determine the microbial contamination of Gouda cheese with and without wax.

\section{MATERIALS AND METHODS}

Samples of Gouda cheese wax were collected from four Iranian dairy manufacturers between April and June 2018. Table 1 shows the specifications of the collected samples.

Culture media including violet red bile lactose agar, mannitol salt agar, lauryl sulfate broth, SS agar and yeast extract glucose chloramphenicol agar were purchased from Merck Co. (Germany) to culture coliforms, $S$. aureus, E. coli, Salmonella and mold and yeast, respectively (12). The standard strains E. coli ATCC 19118, S. aureus ATCC 6538, Saccharomyces cerevisiae PTCC 5074, Aspergillus brasiliensis and Salmonella enterica PTCC 1709 were obtained from the Ibresco Co. (Iran).

According to the Codex C-5; 2013 and Institute of Standards and Industrial Research of Iran (ISIRI) 9013, all collected samples were examined for microbial enumeration of coliforms, E. coli, Salmonella and coagulasepositive Staphylococcus based on ISO 4832, ISO 11866-1, ISO 6785, ISO 6888-3 and ISO 6611 , respectively $(4,5,12-19)$.

The MIC of Gouda cheese wax against the tested microorganisms was determined using the broth microdilution method. First, serial dilutions were prepared from the wax in microbial growth media. The tested microorganisms were added to the wax dilutions and incubated for growth. The examined wax was serially diluted in sterile purified water. Next, $5 \mathrm{ml}$ of each wax dilution were added to $5 \mathrm{ml}$ of $2 \times$ concentrated media. Two media control tubes were prepared by mixing $5 \mathrm{ml}$ sterile purified water with $5 \mathrm{ml}$ of $2 \times$ media $(14,15)$.

All tubes were inoculated with $0.05 \mathrm{ml}$ of the test microorganisms and were incubated at 37 $\pm 2{ }^{\circ} \mathrm{C}$ for $16-20$ hours. Finally, absorption at $620 \mathrm{~nm}$ was read by a spectrophotometer (UNIQO UV2100, USA) to determine bacterial growth.

The MBC was determined as the lowest concentration of cheese wax required to kill the tested microorganisms $(20,21)$. After determining the MIC, the microorganisms were cultured on a culture medium of Muller's Hilton-Agar sterile, and the plates were placed in a $35{ }^{\circ} \mathrm{C}$ incubator for 16 to 18 hours. 
Table 1- Technical specifications of the collected Gouda cheese wax samples

\begin{tabular}{ccccc}
\hline Manufacturers & A & B & C & D \\
\hline Number of samples & 15 & $\mathbf{1 5}$ & $\mathbf{1 5}$ & $\mathbf{1 5}$ \\
Health Code (Ministry of Health) & $\checkmark$ & $\checkmark$ & $\checkmark$ & $\checkmark$ \\
ISO 9001: 2008 & $\checkmark$ & $\checkmark$ & $\checkmark$ & $\checkmark$ \\
ISO 22000: 2005 & $\checkmark$ & $\checkmark$ & $\checkmark$ & $\checkmark$ \\
HACCP & $\checkmark$ & $\checkmark$ & $\checkmark$ & $\checkmark$ \\
Standard Logo & $\checkmark$ & $\checkmark$ & $\checkmark$ & $\checkmark$ \\
Production date and expiration & $\checkmark$ & $\checkmark$ & $\checkmark$ & $\checkmark$ \\
\hline
\end{tabular}

ISO: International organization for standardization

HACCP: Hazard Analysis Critical Control Point

\section{RESULTS}

All wax samples collected from Gouda cheese met the required standards (Table 2).

The results showed that of the tested cheese wax samples had no effects on the growth of the microorganisms. In other words, the collected samples of Gouda cheese wax had no inhibitory effect on E. coli, S. aureus, $S$. cerevisiae, A. brasiliensis and $S$. enterica.

Table 2- The results of contamination of wax of Gouda cheese samples

\begin{tabular}{|c|c|c|c|c|c|c|}
\hline \multicolumn{2}{|c|}{ Gouda cheese wax samples } & \multirow{2}{*}{$\begin{array}{c}\text { Total coliforms }(\mathrm{Cfu} / \mathrm{g}) \\
10>\end{array}$} & \multirow{2}{*}{$\begin{array}{c}\text { E. coli in one gram } \\
\text { Negative }\end{array}$} & \multirow{2}{*}{$\begin{array}{c}\begin{array}{c}\text { Coagulase-positive } \\
\text { Staphylococcus in one } \\
\text { gram }\end{array} \\
\text { Negative }\end{array}$} & \multirow{2}{*}{$\begin{array}{c}\text { Mold and Yeast }(\mathrm{Cfu} / \mathrm{g}) \\
0.3 \times 10^{2}\end{array}$} & \multirow{2}{*}{$\begin{array}{r}\begin{array}{r}\text { Salmonella } \\
\text { in } 25 \text { grams }\end{array} \\
\text { Negative }\end{array}$} \\
\hline Manufacturer A & 1 & & & & & \\
\hline & 2 & $10>$ & Negative & Negative & $0.2 \times 10^{2}$ & Negative \\
\hline & 3 & $10>$ & Negative & Negative & $0.4 \times 10^{2}$ & Negative \\
\hline & 4 & $10>$ & Negative & Negative & $0.6 \times 10^{2}$ & Negative \\
\hline & 5 & 10> & Negative & Negative & $0.5 \times 10^{2}$ & Negative \\
\hline \multirow[t]{5}{*}{ Manufacturer B } & 1 & $10>$ & Negative & Negative & $0.1 \times 10^{2}$ & Negative \\
\hline & 2 & $10>$ & Negative & Negative & $0.1 \times 10^{2}$ & Negative \\
\hline & 3 & $10>$ & Negative & Negative & $0.3 \times 10^{2}$ & Negative \\
\hline & 4 & $10>$ & Negative & Negative & $0.3 \times 10^{2}$ & Negative \\
\hline & 5 & $10>$ & Negative & Negative & $0.5 \times 10^{2}$ & Negative \\
\hline \multirow[t]{5}{*}{ Manufacturer C } & 1 & $10>$ & Negative & Negative & $0.1 \times 10^{2}$ & Negative \\
\hline & 2 & $10>$ & Negative & Negative & $0.1 \times 10^{2}$ & Negative \\
\hline & 3 & 10> & Negative & Negative & $0.3 \times 10^{2}$ & Negative \\
\hline & 4 & $10>$ & Negative & Negative & $0.4 \times 10^{2}$ & Negative \\
\hline & 5 & $10>$ & Negative & Negative & $0.1 \times 10^{2}$ & Negative \\
\hline \multirow[t]{5}{*}{ Manufacturer D } & 1 & $10>$ & Negative & Negative & $0.7 \times 10^{2}$ & Negative \\
\hline & 2 & $10>$ & Negative & Negative & $0.4 \times 10^{2}$ & Negative \\
\hline & 3 & $10>$ & Negative & Negative & $0.1 \times 10^{2}$ & Negative \\
\hline & 4 & $10>$ & Negative & Negative & $0.1 \times 10^{2}$ & Negative \\
\hline & 5 & $10>$ & Negative & Negative & $0.2 \times 10^{2}$ & Negative \\
\hline
\end{tabular}

The results showed that of the tested cheese wax samples had no effects on the growth of the microorganisms. In other words, the collected samples of Gouda cheese wax had no inhibitory effect on $E$. coli, $S$. aureus, $S$. cerevisiae, A. brasiliensis and S. enterica.

\section{DISCUSSION}

Cheese is vulnerable to microbiological deterioration throughout storage, distribution, processing and ripening due to its high water extensive microorganism development at cheese surface, which considerably reduces the 
content and favorable $\mathrm{pH}$ for microbial growth (22). Conditions during ripening often promote cheese quality $(23,24)$. The cheese surface is an open ecosystem with abiotic properties that may be suitable for growth of various microorganisms. Maintaining hygienic conditions during ripening and storage plays a significant role in microbial contamination of cheese surface $(6,25)$. Cheese wax is a special coating used for preventing contamination, moisture retention and shaping cheese. Waxing cheese is a simple method to protect hard cheese from airborne bacteria, unwanted mold and excessive drying. This process is generally applied on semi-hard and hard cheeses. Hard cheese wax is a food-grade, paraffin-based wax. We found that wax samples from Gouda cheese had no inhibitory effect on potential pathogens in Gouda cheese, which is in agreement with two previous studies $(11,23)$.

Coating is a traditional method of maintaining the quality of cheese during shelf life. Cheese can be contaminated with various microorganisms during initial preparation, processing, packaging and storage. Thus, it can be concluded that antimicrobial compounds can improve cheese quality and shelf life $(6,26)$.

Our findings indicated that wax had no role in the prevention of microbial contamination of Gouda cheese. Some studies have investigated production of wax with antimicrobial properties. For instance, Taherkhani et al. used Kermanian Black Cuminin extract in Gouda cheese wax to induce antimicrobial properties

\section{References}

1. Abdel Moneim E, Ohag M, Hassan M, Alreshidi MM, Abdelmageed E, VeettilSome VN. Chemical and Microbiological Characteristics of Gouda Cheese. Journal of Advances in Bioresearch. 2018; 9(3): 32-37. [PubMed] [Google Scholar]

2. Wemmenhove E, Wells-Bennik, Stara A, Hooijdonk, Zwietering M. How $\mathrm{NaCl}$ and water content deter mine water activity during ripening of Gouda cheese, and the predicted effect on inhibition of Listeria monocytogenes. Journal of Dairy Science. 2016; 99(7): 5192-52. [DOI:10.3168/jds.2015-10523] [PubMed] [Google Scholar]

3. Hugenholtz J, Hylckama Vlieg J. A volume in Woodhead Publishing Series in Food Science, Technology and Nutrition. In: Weimer B, editor. Improving the Flavour of Cheese. Monitoring cheese ripening: new developments; 2007; 351- 369. [View at Publisher] [Google Scholar]

[DOI:10.1533/9781845693053.3.351]

4. Codex A. limentarius Commission C-5: 2013. Codex Standard for Gouda. [Google Scholar]
(27). Haniyah et al. reported that eight weeks of ripening Gouda cheese with a composite edible film containing modified lysozyme can effectively inhibit microbial growth both at the surface and inside Gouda cheese (28). Saravani et al. prepared an inhibitory edible coating for Gouda cheese based on whey protein containing lactoperoxidase and Bunium persicum essential oil in order to control postpasteurization contamination. Their results showed that the Bunium persicum essential oil in combination with lactoperoxidase system can be applied as natural antimicrobial agents for extending the shelf life of washed and ripened Gouda cheese (26). Generally, wax can protect cheese against contamination and inappropriate physical conditions to some extent but cannot remove contaminations once the cheese become contaminated. Therefore, it is recommended that dairy manufacturers use active wax or wax with antibacterial capacity in production of cheese $(27,28)$.

\section{CONCLUSION}

The Gouda cheese wax samples collected from Iran have no antimicrobial properties. It is recommended to use Gouda cheese coating with antimicrobial properties to minimize the risk of contamination and spread of microorganisms.

\section{ACKNOWLEDGEMENTS}

None.

\section{CONFLICT OF INTEREST}

The authors declare no conflict of interest.

5. Iranian National Standardization Organization No 9013. Gouda cheese Specifications and test methods. 1st. Revision 2016. [Google Scholar]

6. Joelle K. Salazar, Christina K. Carstens, Padmini Ramachandran, Arlette G. Shazer, Sartaj S. Narula, Elizabeth Reed, Andrea Ottesen and Kristin M. Schill. Metagenomics of pasteurized and unpasteurized gouda cheese using targeted 16S rDNA sequencing. Journal of BMC Microbiology. 2018; 18:189. [DOI:10.1186/s12866-018-1323-4] [PubMed] [Google Scholar]

7. Qanbarzadeh B, Almasi H, Zahedi Y. Biodegradable edible biopolymers in food and drug packaging. Amirkabir University of technology Tehran polytechnic press; 2009. [Google Scholar]

8. Thawien Wittaya. Edible films and coatings characteristics and properties. International Food Research Journal. 2008; 15(3). [Google Scholar] 
9. Cerqueira MA, Alvaro M, Bartolomeu W, Jose A, Renato A, et al. Functional Polysaccharides as Edible Coatings for Cheese. Journal of Agricultural and food chemistry. 2009; 57, 4, 1456-1462. [DOI:10.1021/jf802726d] [PubMed] [Google Scholar]

10. Bourtoom T. Edible films and coatings: characteristics and properties. International Food Research Journal. 2008; 15(3): 237-248. [PubMed] [Google Scholar]

11. Wemmenhove E, Valenberg H, Hooijdonk A, WellsBennik A, Zwietering A. Edible films and coatings: characteristics and propertiesJournal of Food Control. 2018; 84, 413-418. [DOI:10.1016/j.foodcont.2017.08.028] [Google Scholar] 12. Iranian National Standardization Organization No 2406. Microbiology of milk and milk products Specifications and test methods. 3rd .Revision. 2017. [Google Scholar]

13. Ananimus, Microbiological testing of finished dairy products, Dairy food safty Victoria. PP: 1-8, 2013. [Google Scholar]

14. ISO 4832: 2006, Microbiology of food and animal feeding stuffs - Horizontal method for the enumeration of numbers. [PubMed] [Google Scholar]

15. ISO 6611: 2004, Milk and milk products Enumeration of colony-forming units of yeasts and/or molds- colony-count technique at $25^{\circ} \mathrm{C}$. [View at Publisher] [PubMed] [Google Scholar]

16. ISO 6785: 2001 ، Milk and Milk Products - Detection of Salmonella Spp. [View at Publisher] [PubMed] [Google Scholar]

17. Ali Mohammadi, Maryam Hashemi, Masoud Hosseini. Antimicrobial Activity of Essential Oils of Cinnamomum zeylanicum, Mentha piperita, Zataria multiflora Boiss and Thymus vulgaris Against Pathogenic Bacteria. Medical Laboratory Journal. 2016;10(2): 32- 40. [View at Publisher] [DOI:10.18869/acadpub.mlj.10.2.32] [Google Scholar]

18. ISO 11866-1:2005 Milk and .ilk products Enumeration of presumptive Escherichia coli. Coliforms - Colony-mcount technique [View at Publisher]

19. ISO 6888 - 3: 2003, Microbiology of food and animal feeding stuffs -- Horizontal method for the enumeration of coagulase-positive staphylococci (Staphylococcus aureus and other species) - Part 3: Detection and MPN technique for low. [View at Publisher] [Google Scholar]

20. Ehsani A, Rezaeiyan A, Hashemi M, Aminzare M, Jannat B and Afshari A. Antibacterial activity and sensory properties of Heracleum persicum essential oil, nisin, and Lactobacillus acidophilus against Listeria monocytogenes in cheese. Journal of Veterinary World. 2019; 12(1): 90-96. [DOI:10.14202/vetworld.2019.9096] [PubMed] [Google Scholar]
21. Ehsani A, Hashemi M, Naghibi S, Khalili S. https://pubmed.ncbi.nlm.nih.gov/30936660/ournal of Food Safety. 2016; 36)4): 563-570. [DOI:10.1111/jfs. 12277] [Google Scholar]

22. Conte, A., Angiolillo, L., Mastromatteo, M. and Del Nobile, A. Technological options of packaging to control food quality. Food Industry. 2013; 354-379. [DOI:10.5772/53151] [PubMed] [Google Scholar]

23. Antioxidant activity, fatty acids characterization and oxidative stability of Gouda cheese fortified with mango (Mangifera indica L.) kernel fat, Imran Taj Khan, Muhammad Nadeem, Muhammad Imran and Muhammad Ajmal. Sadaqat Ali, Association of Food Scientists \& Technologists (India) 2018. [PubMed] [Google Scholar] 24. Cerqueira, M.A., Lima, A.M., Teixeira, J.A., Moreira, R.A. and Vicente, A.A. Suitability of novel galactomannans as edible coatings for tropical fruits. Journal of Food Engineering. 2009; 94 (3-4): 372-378. [View at Publisher] [DOI:10.1016/j.jfoodeng.2009.04.003] [Google Scholar] 25. Montel MC, Buchin S, Mallet A, Delbes-Paus C, Vuitton DA, Desmasures N, Berthier F. Traditional cheeses: rich and diverse microbiota with associated benefits. International Journal of Food Microbiology. 2014; 177:136-54. [View at Publisher] [DOI:10.1016/j.ijfoodmicro.2014.02.019] [PubMed] [Google Scholar]

26. Saravani M, Ehsani A, Aliakbarlu J, Ghasempourz Z. Gouda cheese spoilage prevention: Biodegradable coating induced by Bunium persicum essential oil and lactoperoxidase system. Journal of Food Science \& Nutrition. 2019; 1- 10. [View at Publisher] [DOI:10.1002/fsn3.888] [PubMed] [Google Scholar]

27. Taherkhani P, Noori N, Akhondzadeh Basti A, Gandomi H, Alimohammadi M. https://pubmed.ncbi.nlm.nih.gov/30918638/. Journal of Medicinal Plants. 2015; 2(54): 76-85. [View at Publisher]

28. Haniyah Y, Purwadi, Radiati L, Thohari I, Setyowati E, Manab A. Gouda Cheese Microbial Controlling During Ripening Using Composite Edible Film Containing Lysozyme. Journal of Current Microbiology and Applied Sciences. 2016; 5(5): 748-756. [DOI:10.20546/ijcmas.2016.505.076] [Google Scholar]

How to Cite:

Mohammadzadeh Vazifeh M, Hosseini SM, Mohammadi A, Jahanfar M, Maleki H[Evolution of Antimicrobial Effects of Gouda Cheese Wax ]. mljgoums. 2021; 15(2): 18-22 DOI: 10.29252/mlj.15.2.18

(c) The authors 